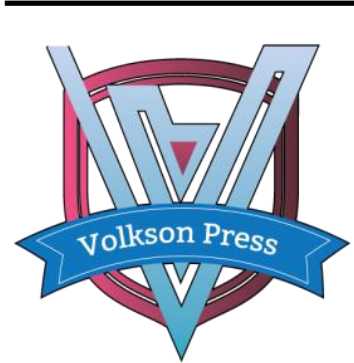

Contents List available at VOLKSON PRESS

Economics \& Management Innovations(EMI)

DOI : http://doi.org/10.26480/icemi.02.2018.48.51

ISBN: 978-1-948012-14-0

\title{
ANALYSIS OF SERVICE QUALITY AND COMPETITIVE STRATEGY OF GREEN TOURISM
}

\author{
Ching-Hsia Su \\ College of Tourism and Service Management, Nankai University, Tianjin 300071, China \\ *Corresponding Author e-mail: maysky566@yahoo.com.tw
}

This is an open access article distributed under the Creative Commons Attribution License, which permits unrestricted use, distribution, and reproduction in any medium, provided the original work is properly cited.

\section{ARTICLE DETAILS}

\section{Article History:}

Received 26 June 2018 Accepted 2 July 2018 Available online 1 August 2018

\section{ABSTRACT}

Green tourism refers to all tourism participants, including tourists, travel agencies, and tour guides, restaurants, and scenic spots, which must respect nature and protect the environment throughout the entire travel process. In the process of green tourism, tourists are no longer just passively admiring and entertaining, but participating in more practical actions to protect the environment, thus, enhancing the environmental awareness of tourists. At present, green and low-carbon tourism products are still in their infancy, and both government agencies and many private enterprises dare not invest too much resources into their green tourism products without careful consideration. Therefore, how to clearly grasp and strengthen the quality factors that can improve consumer satisfaction in the case of resource shortage should be the key to whether tourism products can successfully open the market. This study uses the Importance-Performance Analysis method to determine the factors that truly affect green tourism customer satisfaction, in order to provide future practitioners with design guidelines for developing green and lowcarbon tourism products, and to focus resources for improving key quality factors.

\section{KEYWORDS}

Green tourism, quality factors, Importance-Performance Analysis Model, quality of service, competitive strategy.

\section{INTRODUCTION}

In the past, people mostly sought development at the expense of environmental damage, and then, protected the environment at the expense of development speed. The main root cause is the lack of environmental awareness. In the past, sightseeing and recreation activities were considered to be relatively non-predatory to environmental resources; however, due to the huge increase in the number of people engaged in sightseeing and recreation in recent years, the natural environment, social culture, and livelihood economy of the sightseeing and recreation attractions are disturbed, and even destroyed by unsuitable factors, such as the quality of tourists, the way of use, the degree of use, the time of activities, the location, etc $[1,2]$.

In foreign countries, tourism development with resources from rural areas, fishing villages, and mountain villages is called "green tourism". Because green tourism is targeted at rural areas with idyllic scenery, it is also known as rural tourism or agricultural (or rural) tourism, which was originally developed in Europe after the industrial revolution. Its purpose is to promote the exchange between urban and rural areas [3]. On the one hand, it brings leisure and entertainment to urban residents; on the other hand, it can promote the development of rural areas.

In the past, tourism-related research with environmental protection concepts mostly belonged to the topics of eco-tourism, rural tourism, etc. Taiwan's green tourism-related research mostly discuss the greening mode and benefits of a certain link in the tourism supply chain, such as green home-stays, green consumer behavior, etc. Related researches of green tourism or low-carbon tourism products are rare. However, there are many successful cases and related researches on green tourism in foreign countries, which show that green tourism has promotional value [4].

At present, green tourism products are still in their infancy, and both government agencies and many private enterprises dare not invest too many resources into their green tourism products without careful consideration. Therefore, how to clearly grasp and strengthen the quality factors that can improve consumer satisfaction in the case of resource shortage should be the key to whether tourism products can successfully open the market. This study analyzes the literature content of green tourism and intends to determine the quality factors that influence customer satisfaction in green tourism, in order to provide future practitioners with design guidelines for developing green tourism products and analyzes the competitive strategy of practitioners.

\subsection{Literature Review-Green Tourism}

With the changes of the times, the deterioration of the global environment has caused climate anomalies, thus, the content of green tourism has also changed with the gradual increase in environmental awareness. Training is no longer the previous method of only raising environmental awareness through rural tourism; instead, it reduces the interference of tourism to the environment with a more positive attitude through changing the way of tourism [5].

The so-called green tourism refers to all tourism participants, including tourists, travel agencies and tour guides, restaurants, and scenic spots, which must respect nature and protect the environment throughout the entire travel process. In the process of green tourism, tourists are no longer just passively admiring and entertaining, but participate in more practical actions to protect the environment, thus, enhancing the environmental awareness of tourists.

Thea further pointed out that green tourism is the use and utilization of resources and the environment through the principles of reduction, reuse, and recycling during operation, which can achieve high efficiency of resource utilization and meet the requirements of the economic development model with minimum environmental damage. Green and environmental protection are closely integrated, thus, consumers can understand nature while enjoying nature. Tsai believed that green tourism is a brand-new tourism model that promotes the concept of green consumption, and green consumption behavior, as well as the sustainable 
development of tourism resources and tourism. Effective forms of green tourism include: cultivate green concepts, promote green standards, implement green development, produce green products, and develop green businesses.

Simpson et al. ${ }^{4}$ believed that green tourism is actually a low-carbon lifestyle for individuals, and there are 3 key points to transform it into tourism actions [6]:

(1) Transform the existing tourism model, advocate mass transportation, gas-electric hybrid vehicles, electric vehicles, bicycles, and other lowcarbon or carbon-free methods, while enriching tourism life and increasing tourism projects.

(2) Change the ethos of luxury and waste, strengthen cleanliness, convenience, and comfortable functionality, and enhance the brand of culture.

(3) Strengthen the development of tourism intelligence, improve operational efficiency, introduce energy-saving and carbon-reduction technologies, reduce carbon emissions, and finally, form a circular economy model of the entire supply chain.

In fact, there are many green tourism organizations abroad. Most of them are non-governmental organizations that have proposed a series of green guidelines for their domestic tourism industry through certification, training, incentives, and other methods. The famous green tourism organizations include: Toronto Green Travel Association, Green Globe 21, UK Tourism and Environment Forum, etc. The Green Tourism Association of Taiwan (GTAT) was officially established in Taipei on July 28, 2010. It is mainly composed of tourism practitioners, hotels and home-stays, agriculture and forestry park practitioners, environmental energy conservation and leisure tourism scholars, education and fitness professionals, public and private organizations, and individuals related to green tourism.

Its purpose is to promote ecological and energy-saving carbon-reducing tourism, and it hopes to become the green tourism education platform for Taiwan's green tourism-related industry marketing and public and private institutions, in order to establish a comprehensive green tourism network that combines green tourism products, leisure associations, low-carbon activities, and environmental education. Moreover, it strives to achieve the goal of becoming the green footprint certification unit in tourism [7].

Based on the aforementioned literature discussion, this study proposes 9 measurement indicators of green tourism quality factors to measure the performance of green tourism service quality. Please refer to Table 1 below for details of these 9 indicators.

\section{RESEARCH METHOD}

\subsection{Importance-Performance Analysis}

Importance-Performance Analysis (IPA) was first proposed by Martilla and James ${ }^{10}$ for basic architecture and practical application [8-13]. IPA plots the importance and average performance scores of an attribute in a two-dimensional graph, where the vertical axis represents importance and the horizontal axis represents performance, as shown in Figure 1 [1419].

The four quadrants in the IPA method each have their own definition:

(1) Keep up the good work: Indicates that customers attach great importance to the attributes of the area and are satisfied with the performance of the company. Therefore, this attribute falls in the quadrant of "Keep up the good work".

(2) Concentrate here: Indicates that customers attach great importance to the attributes of the area but are not satisfied with the performance of the company. Therefore, this attribute falls in the quadrant of "Concentrate here".

(3) Low priority: Indicates that customers attach little importance to the attributes of the area and are not satisfied with the performance of the company. Therefore, this attribute falls in the quadrant of "Low priority".

(4) Possible overkill: Indicates that customers attach little importance to the attributes of the area but are satisfied with the performance of the company. Therefore, this attribute falls in the quadrant of "Possible overkill".
Through the division of different regions, managers can make the most effective use of limited resources and provide the priority ranking of improvements to enhance satisfaction [20-25]. The IPA analysis method can easily analyze the quality and improvement of attributes, and it has been widely cited by many scholars in other fields as a tool for analyzing attributes to improve priority ranking and satisfy customer needs [26-28]

\begin{tabular}{l|l} 
Concentrate here & Keep up the good work \\
\hline Low priority & Possible overkill \\
\hline &
\end{tabular}

Figure 1: Importance-Performance Analysis

\subsection{Research cases}

Company A is in the top 5 travel companies in Taiwan. In this study, Company A is taken as the object of the case study to evaluate the green tourism quality and performance of the case company, which is used as the basis for improvement of the case company. This questionnaire uses a Likert seven-point scale, which has a total of 9 questions. The questionnaire started from April 5, 2018 to April 26, 2018, which investigated 420 customers of Company A, a total of 420 formal questionnaires were issued, and 308 valid questionnaires were responded, for an effective respond rate of $73.33 \%$.

\section{RESEARCH RESULTS AND DISCUSSION}

In this study, the importance mean value (5.76) and the performance mean value (5.77) in the questionnaire are used as standard coordinates to determine whether each quality factor performs well or poorly. Please see Table 1 for details. According to the IPA analysis results, Company A belongs to "Keep up the good work" in 3 indicators (2) use public transit or shuttle bus to reach destinations, (4) both tour guides and local residents are committed to maintaining the local environment, (7) tour guides do not damage the environment at will during the tour. These are advantages of Company X, and it must maintain them to maintain its service quality performance and help the company win the reputation of green tourism.

Company A has competitive disadvantage in 3 indicators (1) local food specialties mainly use local food materials, (3) tour guides introduce local natural ecology and historical humanities detailedly and professionally, (5) integrate green concepts into local sightseeing seasons or festivals, which belongs to "Concentrate here". Company X must pool its resources to enhance the performance of these 3 criteria in order to reverse the disadvantages and improve its competitive power.

In addition, Company A belongs to "Low priority" in the indicator of (8) it does not interfere with the local ecological environment during the tour. In terms of this indicator, Company A does not perform well; however, as its importance is low, it can be placed in the final position, meaning it may be improved when the company has extra resources.

Finally, the 2 indicators of (6) tour guides encourage tourists to participate in the lives of local residents and understand local culture and (9) use "green tourism" as the advertising slogan have low importance; however, as company A's performance is high, they belong to "Possible overkill". While Company A performs well, they cannot bring better performance to the company, thus, it should be considered to transfer the company resources to other indicators. Please see Table 1 for details. 
Table 1: The Importance-Performance Analysis of Green Tourism Products' Service Quality

\begin{tabular}{|c|c|c|c|c|}
\hline Item & Quality factor & Importance & Performance & Competitive strategy \\
\hline 1 & Local food specialties mainly use local food materials. & 5.9 & 5.6 & Concentrate here \\
\hline 2 & Use public transit or shuttle bus to reach destinations. & 5.9 & 5.9 & $\begin{array}{l}\text { Keep up the good } \\
\text { work }\end{array}$ \\
\hline 3 & $\begin{array}{l}\text { Tour guides introduce local natural ecology and historical humanities detailedly and } \\
\text { professionally. }\end{array}$ & 5.8 & 5.1 & Concentrate here \\
\hline 4 & $\begin{array}{l}\text { Both tour guides and local residents are committed to maintaining the local } \\
\text { environment. }\end{array}$ & 6.0 & 6.3 & $\begin{array}{l}\text { Keep up the good } \\
\text { work }\end{array}$ \\
\hline 5 & Integrate green concepts into local sightseeing seasons or festivals. & 6.1 & 5.6 & Concentrate here \\
\hline 6 & $\begin{array}{l}\text { Tour guides encourage tourists to participate in the lives of local residents and } \\
\text { understand local culture. }\end{array}$ & 5.5 & 6.0 & Possible overkill \\
\hline 7 & Tour guides do not damage the environment at will during the tour. & 5.9 & 5.9 & $\begin{array}{l}\text { Keep up the good } \\
\text { work }\end{array}$ \\
\hline 8 & It does not interfere with the local ecological environment during the tour. & 5.4 & 5.6 & Low priority \\
\hline 9 & Use "green tourism" as the advertising slogan. & 5.3 & 5.9 & Possible overkill \\
\hline Average & & 5.76 & 5.77 & \\
\hline
\end{tabular}

\section{CONCLUSION}

At present, green and low-carbon tourism products are still in their infancy, and both government agencies and many private enterprises dare not invest too much resources into their green tourism products without careful consideration. Therefore, how to clearly grasp and strengthen the quality factors that can improve consumer satisfaction in the case of resource shortage should be the key to whether tourism products can successfully open the market.

This study proposed 9 measurement indicators for the service quality of green tourism to measure the performance and competitive strategy of green tourism quality, and then, the research results were used as the basis for the improvements of the case company. According to the IPA analysis results, Company A has competitive advantages in the 3 service quality indicators of (2), (4) and (7), meaning they are advantages of Company A, and it must maintain them to maintain its service quality performance. However, Company A has competitive disadvantages in the 3 service quality indicators of (1), (3) and (5). Company X must pool resources to enhance its performance of these 3 criteria, in order to reverse the disadvantages and improve competitive power.

\section{REFERENCES}

[1] Rust, R.T., Kannan, P.K. 2003. E-Service: A New Paradigm for Business in the Electronic Environment. Communications of the ACM, 46 (6), 37-42.

[2] Aladwani, A.M. 2001. Online Banking: A Field Study of Drivers, Development Challenges, and Expectations. International Journal of Information Management, 21 (3), 213-225.

[3] Sayar, C., Wolfe, S. 2007. Internet Banking Market Performance: Turkey Versus the UK. International Journal of Bank Marketing, 25 (3), 122-141.

[4] Tsai, S.B., Li, G., Wu, C.H., Zheng, Y. 2016. An empirical research on evaluating banks' credit assessment of corporate customers. SpringerPlus, 5, 2088. DOI 10.1186/s40064-016-3774-0.

[5] Zhang, X., Deng, Y., Chan, F.T., Xu, P. 2013. IFSJSP: A novel methodology for the Job-Shop Scheduling Problem based on intuitionistic fuzzy sets. International Journal of Production Research, 51 (17), 5100-5119.

[6] Tsai, S.B., Chen, K.Y., Zhao, H., Wei, Y.M. 2016. Using a Mixed Model to Explore Evaluation Criteria for Bank Supervision: A Banking Supervision Law Perspective. PLoSONE, 11 (12), e0167710.

[7] Zeithaml, V.A., Parasuraman, A., Malhotra, A. 2002. Service Quality Delivery through Web Sites: A Critical Review of Extant Knowledge. Academy of Marketing Science, 30 (4), 362-375.

[8] Martilla, J.A., James, J.C. 1977. Importance-Performance Analysis. Journal of Marketing, 41 (1), 77-79.

[9] Tsai, S.B., Wei, Y.M., Chen, K.Y., Xu, T. 2016. Evaluating Green Suppliers from Green Environmental Perspective. Environment and Planning BPlanning and Design, 43 (5), 941-959.

[10] Tsai, S.B. 2016. Using Grey Models for Forecasting China's Growth Trends in Renewable Energy Consumption. Clean Technologies and Environmental Policy, 18, 563-571.
[11] Guo, J.J., Tsai, S.B. 2015. Discussing and Evaluating Green Supply Chain Suppliers: A Case Study of the Printed Circuit Board Industry in China. South African Journal of Industrial Engineering, 26 (2), 56-67.

[12] Tsai, S.B., Huang, C.Y., Wang, C.K., Chen, Q. 2016. Using a Mixed Model to Evaluate Job Satisfaction in High-Tech Industries. Plos One, 11 (5), e0154071. doi: 10.1371/journal.pone.0154071

[13] Lee, Y.C., Chu, W.H., Chen, Q., Tsai, S.B. 2016. Integrating DEMATEL Model and Failure Mode and Effects Analysis to Determine the Priority in Solving Production Problems. Advances in Mechanical Engineering, 8 (4), $1-12$.

[14] Tsai, S.B., Xue, Y., Zhang, J., Chen, Q. 2016. Models for Forecasting Growth Trends in Renewable Energy. Renewable and Sustainable Energy Reviews, DOI: 10.1016/j.rser.2016.06.001

[15] Qu, Q., Chen, K.Y., Wei, Y.M. 2015. Using Hybrid Model to Evaluate Performance of Innovation and Technology Professionals in Marine Logistics Industry Mathematical Problems in Engineering, Article ID 361275, 8 pages, http://dx.doi.org/10.1155/2015/361275.

[16] Zhou, J., Wang, Q., Tsai, S.B. 2016. How to Evaluate the Job Satisfaction of Development Personnel. IEEE Transactions on Systems Man Cybernetics-Systems, 10.1109/TSMC.2016.2519860.

[17] Su, J.M., Lee, S.C., Tsai, S.B., Lu, T.L. 2016. A comprehensive survey of the relationship between self-efficacy and performance for the governmental auditors. Springer Plus, 5, 508. DOI 10.1186/s40064-0162104-x.

[18] Tsai, S.B., Lee, Y.C., Guo, J.J. 2014. Using modified grey forecasting models to forecast the growth trends of green materials. Proceedings of the Institution of Mechanical Engineers, Part B. Journal of Engineering Manufacture, 228 (6), 931-940.

[19] Chen, H.M., Wu, C.H., Tsai, S.B., Yu, J. 2016. Exploring key factors in online shopping with a hybrid model. Springer Plus, 5, 2046. DOI 10.1186/s40064-016-3746-4.

[20] Deng, X.Y., Hu, Y., Deng Y., Mahadevan, S. 2014. Environmental impact assessment impact assessment based on numbers. Expert Systems with Applications, 41 (2), 635-643.

[21] Wang, J., Yang, J., Chen, Q., Tsai, S.B. 2016. Collaborative Production Structure of Knowledge-sharing Behavior in Internet Communities. Mobile Information Systems, Article ID 8269474, 9 pages, http://dx.doi.org/10.1155/2016/8269474.

[22] Wang, J., Yang, J., Chen, Q., Tsai, S.B. 2016. Creating the Sustainable Conditions for Knowledge Information Sharing in Virtual Community. Springer Plus, 5, 1019. DOI 10.1186/s40064-016-2702-7

[23] Lee, Y.C., Wang, Y.C., Chien, C.H., Wu, C.H. 2016. Applying Revised Gap Analysis Model in Measuring Hotel Service Quality. Springer Plus, 5, 1191. DOI 10.1186/s40064-016-2823-z.

[24] Lee, Y.C., Wang, Y.C., Lu, S.C., Hsieh, Y.F. 2016. An Empirical Research on Customer Satisfaction Study: A Consideration of Different Levels of 
Performance. Springer Plus, 5, 1577, DOI 10.1186/s40064-016-3208-z.

[25] Chin, T., Tsai, S.B., Fang, K., Zhu, W. 2016. EO-Performance relationships in Reverse Internationalization by Chinese Global Startup OEMs: Social Networks and Strategic Flexibility. PLoS ONE, 11 (9), e0162175. doi: 10.1371/journal.pone.0162175

[26] Lee, S.C., Su, J.M., Tsai, S.B., Lu, T.L. 2016. A comprehensive survey of government auditors' self-efficacy and professional Development for improving audit quality. Springer Plus, 5, 1263. DOI 10.1186/s40064-016-
2903-0

[27] Chen, H.M., Wu, C.H., Tsai, S.B., Yu, J. 2016. Exploring key factors in online shopping with a hybrid model. Springer Plus, 5, 20-46. DOI 10.1186/s40064-016-3746-4.

[28] Ge, B., Jiang, D., Gao, Y., Tsai, S.B. 2016. The Influence of Legitimacy on a Proactive Green Orientation and Green Performance: A Study Based on Transitional Economy Scenarios in China. Sustainability, 8, 1344, 1-20. 